D. Cross

\title{
An unhealthy obsession with fluoride
}

ABSTRACT. Justification for a state policy on water fluoridation is found in the authoritarian approach to public health. The strategies employed to choose interventions are consistent with strictly utilitarian determinants that in practice rely on inadequate risk cost-benefit analysis, inflating the perceived benefits to the State whilst ignoring private sector costs when the socioeconomic benefits to the State and the community are judged to justify abrogation of individual rights. This promotes reliance on the concept of proportionality in public health interventions, obstructing appropriate review of the ethical acceptability and legitimacy of water fluoridation. It is proposed that the underlying drive to retain fluoridation is mainly directed at preserving the power base of the dental profession; its persistence is reliant on collusion between the legislature itself and its regulatory and implementing agencies, and the tactics employed to maintain the status quo are everywhere dependent on a legal fiction, as well as on scientific fraud and deliberate misrepresentation. It appears, then, that the objective is to persuade key public sector influence groups to recruit the lay public's support through the engineering of misinformed consent to the practice. This new cross-disciplinary analysis examines the underlying ethical and legal issues raised by fluoridation, and the role of the public sector and professional elites in manipulating the judiciary and State (including local authorities) to endorse the preservation of the expiring fluoridation paradigm.

Keywords: inequalities, fluoridation, fluorosis, health belief model, law, public health, statistics

Nanotechnology Perceptions 11 (2015) 169-185 